\title{
OS DIREITOS HUMANOS COMO COMPETÊNCIA DE AVALIAÇÃO NAS REDAÇÓES DO ENEM
}

\author{
Francisco Morilhe Leonardo ${ }^{1}$
}

\begin{abstract}
Resumo: O objetivo do presente estudo é refletir acerca da necessidade dos jovens egressos do Ensino Médio de terem algum embasamento teórico-jurídico em relação aos Direitos Humanos a fim de desenvolverem os temas das redaçôes do Exame Nacional do Ensino Médio (ENEM). Ademais, é clara a omissão do Estado na oferta deste conteúdo, uma vez que, uma das competências deste exame visa à resolução de uma situação-problema cujo tema deverá envolver diferentes textos que tratem de assuntos atuais, pois a proposta de intervenção deve ser dialógica com o texto e em consonância com os Direitos Humanos, na qual, se a mesma estiver em dissonância com estes direitos, haverá a perda de pontos do texto avaliado. Nesse viés, desde o surgimento deste exame vislumbrou-se o compromisso de que os assuntos tratem de questóes de ordem política, social, cultural ou científica, porém, torna-se um obstáculo para o avaliado, uma vez que tais noçôes jurídicas não são adquiridas durante o período na escola regular, em que assiste ao governo a função de prover a educação de forma integral, pois esta é a chave mestra para o sucesso de uma nação.
\end{abstract}

Palavras-chave: Direitos Humanos. Educação. Competências do ENEM. Ensino Médio. Noções Jurídicas.

\section{HUMAN RIGHTS AS A COMPETENCE OF EVALUATION IN ENEM'S EDITIONS}

\begin{abstract}
The aim of the present study is to reflect on the need for young high school graduates to have some theoretical-legal basis in relation to Human Rights in order to develop the themes of the essays of the National High School Exam (ENEM). In addition, the State's omission in offering this content is clear, since one of the competences of this exam aims at solving a problem situation whose theme should involve different texts dealing with current issues, as the intervention proposal must be dialogical with the text and in line with Human Rights, in which, if it is in dissonance with these rights, there will be a loss of points in the evaluated text. In this bias, since the appearance of this examination, the commitment that the subjects deal with political, social, cultural or scientific issues has been glimpsed, however, it becomes an obstacle for the appraised, since such legal notions
\end{abstract}

1 Mestre em Didática do Ensino do Direito pelo UNIVEM - Centro Universitário Eurípedes de Marília-SP. 
are not acquired during the period in regular school, in which the government assists the function of providing education in an integral way, as this is the master key for the success of a nation.

Keywords: Human Rights. Education. Competences of the ENEM. High school. Legal Notions.

\section{INTRODUÇÃO}

Diante de uma sociedade ainda marcada pela desigualdade, violência e práticas autoritárias é possível pensar e atuar no sentido da construção de uma cultura de direitos humanos de modo que isso afete a qualidade de vida dos brasileiros. Nesse sentido, esses direitos assumem uma relevância inegável nas relaçôes sociais e pessoais, sobretudo, pela conjuntura da sociedade atual, a saber, o enfraquecimento da educaçáo, carente de um conteúdo jurídico nas escolas regulares, tais como o conhecimento básico dos direitos e garantias fundamentais, elencados na Carta Magna, e a constante degradação das condições de ensino.

Assiste-se, como estratégia de inserçáo educacional, em face dos novos desafios pedagógicos e sociais, como a falta de qualidade e estrutura do Ensino Médio, especialmente o público e, de igual modo, o reduzido número de vagas nas Universidades, à crescente busca dos conteúdos amalgamada ao espírito da competitividade de vestibulandos em busca de vagas em universidades, submetendo a procura por cursos pré-vestibulares.

Essa lógica torna-se perversa à medida que póe em xeque o papel do Estado que limita os alunos quando se percebe a cobrança de conteúdos voltados aos Direitos Humanos, o que não é estudado na escola regular. Assim, aos estudantes, negam-lhes não só o caráter social, como também a arrancar-lhes a essência do ensino, isto é, a de exigir o conhecimento específico destes direitos numa avaliação de suma importância para o ingresso ao Ensino Superior, e o nítido desequilíbrio no fato de não os ofertar durante o Ensino Médio.

De igual modo, a ausência da oferta do ensino básico sobre os Direitos Humanos revela-se na tentativa de instaurar óbices aos vestibulandos em busca de tal conhecimento, entre as quais, as escolas preparatórias que, muitas vezes, só é opçáo para o aluno que possui condiçôes financeiras para arcar com a mensalidade. Isto posto, o Estado vem sendo responsável por ferir a dignidade do educando por meio da ausência da oferta do ensino para esta competência ao qual consta nos critérios de avaliação que é objeto de avaliação das redaçôes do ENEM.

O que há, porém, de fundamental a salientar é que, mesmo em face dessa atuação precária do Estado na educaçáo, e, igualmente, posto náo haver no ordenamento da educação básica específica uma orientação a disciplinar tal prática vaga. $\mathrm{O}$ tema assume relevância se houvesse a oferta básica do Direito às escolas regulares como uma resposta afirmativa do aluno, qual seja, confiar na efetividade do direito à Educação, o qual lhe é assegurado, sobretudo, pela Constituição Federal de 1988.

Assim sendo, busca-se, neste trabalho, promover reflexôes acerca da competência que visa avaliar os conhecimentos do candidato cuja proposta de 
intervenção para o problema abordado deverá demonstrar respeito aos Direitos Humanos, mas, em contrapartida, o Estado não oferece, durante o Ensino Médio, um meio hábil a fim de que o aluno tenha condiçóes para elaborar um texto à contento, uma vez que desconhece a noçáo exigida neste critério.

Dessa maneira, este trabalho move-se na tentativa de analisar os Direitos Humanos e educação; revisitar as concepçóes teóricas acerca da educação em Direitos Humanos e o critério de avaliaçáo que envolve este tema que o ENEM requer dos candidatos na prova de redação, de modo a compreendê-la na sua dinâmica e, a seguir, delinear a necessidade do embasamento teórico-jurídico em benefício dos educandos a fim de contribuir, não somente com a cidadania.

O Estado deveria atuar como intérprete das demandas ocorridas nesse contexto, à luz dos Direitos Humanos e fundamentais e do princípio da dignidade humana. Ademais, a adoção de uma metodologia de interpretaçáo permite descrever as competências e habilidades nos diferentes níveis, possibilitando definir os pontos nos quais as categorias de resposta das competências são dominadas. Portanto, objetiva-se demonstrar que o conhecimento básico sobre os Direitos Humanos, nas escolas regulares, pode contribuir para a formação integral dos educandos e aperfeiçoar a apresentação nos resultados do ENEM e ser útil para melhorar as notas da redação.

Em decisão recente, o Supremo Tribunal Federal decidiu que não será atribuído a nota zero ao texto que ferir aos Direitos Humanos, como vinha sendo até então, mas poderá perder pontos. Assim sendo, a alegação advinda deste Tribunal é que a regra anterior atentava contra a liberdade de expressão e que o estudante deve sempre realizar a elaboração textual com segurança jurídica e tranquilidade necessária.

Em suma, é relevante sublinhar, que a pesquisa realizar-se-á sob o enfoque dedutivo, a ter como início os fundamentos sobre tais direitos e educação e, a partir deles, atingir os interessados tendo por escopo abstrair as possíveis conclusóes. Estabelecer-se-á no levantamento bibliográfico, além da pesquisa qualitativa, primando à importância de lê-los à luz do saber relativo aos Direitos Humanos.

\section{OS DIREITOS HUMANOS E EDUCAÇÃO}

A educação é preciosa por ser o mais eficaz mecanismo para o desenvolvimento pessoal e, desse modo, assume a condição de direito humano, pois faz parte da dignidade humana e auxilia para acrescê-la com instrução, compreensão e discernimento. Dessa forma, dispóe-se de direito social porque, no bojo da comunidade, fomenta o pleno desenvolvimento da personalidade do cidadáo e, de igual sorte, o direito econômico se caracteriza, nesse viés, de modo a favorecer a autossuficiência econômica por intermédio do emprego ou do trabalho autônomo.

Em se tratando de direito cultural, em nível internacional há a orientação acerca de a educação auxiliar a construção de uma cultura universal em Direitos 
Humanos, haja vista que é fundamental para que se atue plenamente como cidadáo na sociedade hodierna.

Ao postularem a educaçáo como um direito, os autores da Declaração Universal dos Direitos Humanos basearam-se, axiomaticamente, na noção de que a educação não é neutra em relação a valores. Com esse espírito, o Artigo 26 estabelece uma série de metas educacionais, analisadas aqui juntamente com a discussão que focaliza a educação para os Direitos Humanos à luz do citado artigo (CLAUDE, 2005).

Nesse diapasão, a Educação para os Direitos Humanos é um ideal em longo prazo a ser instituído e guiado para as necessidades das futuras geraçóes. Assim, nessa educação para o futuro é necessária ter um bom alicerce, todavia devem-se elaborar programas educacionais criativos cujo escopo é fomentar o desenvolvimento da cidadania, a paz, a democracia e o respeito ao próximo e ao Estado de Direito.

Refletindo essas aspiraçóes, a Assembleia Geral da Organização das Nações Unidas aprovou a Resoluçáo 49/184, que instituiu a Década das Naçóes Unidas para a Educação em matéria de Direitos Humanos - 1995-2004. Ao fazer isso, a comunidade internacional identificou a educação para os direitos humanos como uma estratégia importante para o "desenvolvimento de uma cultura universal dos Direitos Humanos" (CLAUDE, 2005, p. 38).

No caso em apreço, o autor realça a necessidade da inserção da educação popular, ou seja, se origina e se nutre dos processos educativos por meio dos movimentos sociais, desafiando outros espaços da educação, lida com distintos saberes, convivências e práticas e é posicionada e comprometida com o cunho social e político, de modo a interagir entre esses termos.

A Educação Popular é comprometida com a construção de uma sociedade justa, democrática. Ela parte da realidade da populaçáo, disseminada pelos movimentos sociais e valoriza a dialogicidade, a horizontalidade e o conhecimento prévio do sujeito. Promove a autonomia por meio da ação-reflexão-ação. É a expressão do movimento cultural (LIU et al., 2011). Assim, pode-se dizer que a Educação Popular é uma Educação para os Direitos Humanos, uma vez que "promove a mobilizaçáo social para lutar por direitos e construção de valores de respeito e de alteridade" (LIU et al., 2011, p. 34).

Nesse panorama, o direito à educação na Declaração Universal dos Direitos Humanos, assim, com o objetivo de levar a paz ao mundo, pois os membros da Comissão iniciaram os trabalhos em 1947, e Eleanor Roosevelt foi eleita para presidi-la e desde o início todos os integrantes da Comissáo sabiam que a tarefa de elaborar uma declaraçáo dos Direitos Humanos era, em si, uma empreitada educacional. Assim:

Precisamos elaborar uma declaração geral dos direitos humanos definindo em termos sucintos os direitos e as liberdades fundamentais de [todos] que, segundo a Carta, a Organização das Naçóes Unidas deve promover. [...] Esse respeitável anúncio dos direitos fundamentais exercerá uma poderosa 
influência doutrinária, moral e educacional nas mentes e no comportamento das pessoas de todo o mundo (MALIK, 1950, p. 4-5).

Por isso, o referido artigo, em sua seção mais controversa, determina que o direito à educação deve se vincular a três objetivos específicos: (1) pleno desenvolvimento da personalidade humana e fortalecimento do respeito aos direitos do ser humano e às liberdades fundamentais; (2) promoção da compreensão, da tolerância e da amizade entre todas as naçôes e a todos os grupos raciais e religiosos; e (3) incentivo às atividades da ONU para a manutenção da paz (DECLARAÇÃO UNIVERSAL DOS DIREITOS HUMANOS, 1948).

Nessa linha de raciocínio, o tema Direitos Humanos na Educação Básica enreda consideraçóes acerca da função dessa educação e a da escola na construção dos cidadãos e destaca algumas açôes programáticas. Assim sendo, tem-se a educação como a pedagogia educacional voltada a esses direitos, principalmente, quando compreendida como dinâmica e mecanismos que envolvem os movimentos sociais e, os tais movimentos sociais são inerentes à educação em Direitos Humanos.

O assunto sobre a educação em Direitos Humanos tem grande importância e a identifica, na Declaraçáo Universal dos Direitos do Homem, de 1948, que a educaçáo deve visar à plena expansão da personalidade humana e ao reforço dos direitos do Homem e das liberdades fundamentais (DECLARAÇÃO UNIVERSAL DOS DIREITOS HUMANOS, 1948), e se guiou uma nova ideia acerca dos direitos humanos, como universais e indivisíveis devendo o ensino ser acessível para todas as classes sociais.

Assim, a educação em direitos humanos, estabelecida no Plano Mundial de Educação em Direitos Humanos (PMEDH), em seu terceiro item, inclui "educação", "treinamento" e "informação". Esta distinção é crucial e demanda definir conceitualmente do que se está falando quando se refere à educaçáo em um contexto que a distinga de treinamento e informaçáo. Está claro que nesta visão mais ampla de educação estão incluídos, também, valores, atitudes e comportamentos (REGO, 2010).

Por outro prisma, a educação formal tem objetivos claros e específicos e é representada principalmente pelas escolas e universidades. Ela depende de uma diretriz educacional centralizada como o currículo, com estruturas hierárquicas e burocráticas, determinadas em nível nacional, com órgãos fiscalizadores dos ministérios da educação (GADOTTI, 2005).

Cabe salientar que, a Proposta Curricular de Sociologia para o Ensino Médio, do Estado de São Paulo, descreve sucintamente o tema acerca dos Direitos Humanos, o que não é suficiente para satisfazer a demanda que o ENEM exige no que tange a quinta competência de avaliação das redaçóes. Assim, é descrito que deverá ser abordado "O que é cidadania? - O significado de ser cidadão ontem e hoje. - Direitos civis, direitos políticos, direitos sociais e Direitos Humanos" (SÃO PAULO, 2009, p. 08). 
Destarte, conquanto o objetivo da educação vise ao preparo do educando para a vida em sociedade, tal ideal exige, primeiramente, que um método de ensino lhe proporcione a interação entre os alunos com o Direito, cultura e educação, de forma respeitosa e prazerosa, fazendo-os perceberem os limites, deveres e os seus direitos em relação ao próximo. Sobre tal interação, Freire (2011, p. 59) ensina que:

Não houvesse esta integração, que é uma nota de suas relaçóes, e que se aperfeiçoa a medida que a consciência se torna crítica, fosse ele apenas um ser da acomodação ou do ajustamento, e a história e a cultura, domínios exclusivamente seus, não teriam sentido (FREIRE, 2011, p. 59).

O Direito poderia contribuir, se integrar as disciplinas das Ciências Humanas como, Sociologia, Geografia, História, Filosofia no preparo do educando para a vida em sociedade se forem ministradas atividades envolvendo temas transversais dessas disciplinas, de forma interdisciplinar, pois questóes que envolvam os Direitos Humanos perpassam as diferentes disciplinas e não são exclusividade de uma. Em face dessa conjuntura, depreende-se que o educando, ainda no Ensino Médio, se completos dezesseis anos, a lei brasileira lhe permite ao alistamento eleitoral, conferindo-lhe a possibilidade de participação política.

Assim, considera-se um fator primacial em relação à responsabilidade em lhe conferir tais direitos, na qual se revela primordial o preparo para tal exercício da cidadania, que deveria incluir noçóes jurídicas nas escolas regulares desde a Educação Infantil, instruindo-o acerca dos direitos humanos, noçôes de justiça, dos direitos garantidos pela Carta Magna, entre outros. Todavia, a Lei de Diretrizes e Bases da Educação Nacional, de 1996, destaca a relevância dos temas transversais, em que se poderiam incluir os Direitos Humanos e prevê que o currículo voltado aos jovens durante o Ensino Médio deverá dispor sobre:

Artigo 26, $\$$ 9o da LDB/1996: Conteúdos relativos aos direitos humanos e à prevenção de todas as formas de violência contra a criança e o adolescente serão incluídos, como temas transversais, nos currículos escolares de que trata o caput deste artigo, tendo como diretriz a Lei $\mathrm{n}^{\circ} 8.069$, de 13 de julho de 1990 (Estatuto da Criança e do Adolescente), observada a produçáo e distribuição de material didático adequado (BRASIL, 1996).

Por fim, pode-se concluir que, com fulcro no disposto na Lei de Diretrizes e Bases da Educação Nacional, de 1996, as noçôes sobre temas voltados aos Direitos Humanos são necessárias e beneficiariam o educando, seja pela função de contribuir para formação cidadã, seja para beneficiá-lo nas elaboraçôes textuais das redaçôes, onde assiste ao Estado a missão de unir esse ideal e encurtar a distância dessas noçôes à escola de ensino regular, visando à democracia jurídica e da isonomia educacional.

\section{A QUINTA COMPETÊNCIA DA REDAÇÃO DO ENEM - "RESPEITAR OS DIREITOS HUMANOS”.}

Inicialmente, é imperioso destacar que a prova de redação do ENEM está presente desde o primeiro exame no ano de 1998. Nesse viés, fora abordado temas 
que envolviam a ordem social e cultural e, sobretudo, todos os temas relacionados ao Direito, de cujos reflexos manifestam nos cotidianos políticos, históricos nacionais e a cidadania, ocasionando ao candidato a construçáo crítica do assunto.

Ademais, o ENEM tem como objetivo avaliar, em seu modo de correção da prova de redação, a dissertação de uma proposta de intervenção contendo assuntos de cunho social, uma vez que os temas das propostas são, comumente, contextualizados no cenário nacional. Dessa maneira, a quinta e derradeira competência da linha de correção é a responsável por analisar e avaliar tal proposta social que o aluno deverá elaborar.

Destaca-se, desse modo que a grade de pontuação desta quinta competência atesta, primeiramente, se existe ou não uma proposta de intervençáo social na redação que está sendo corrigida. Após esta verificação, caso não haja nenhuma menção a nenhuma proposta de intervenção social, o corretor atribuirá nota zero para este texto; caso haja uma proposta de intervenção social, o avaliador pensará em qual faixa de nota (de 40 a 200 pontos) a redação se encaixa (PEREIRA, 2014).

Há de salientar, todavia, que a orientaçáo básica a fim de se explicitar o elo entre a tese e a proposta de intervençáo social visa a retomar a ideia principal, sendo que, a tese, na conclusão tem que estar concatenada com a proposta que finda a problematizaçáo, demostrando coerência e fluidez entre elas. Outrossim, é importante que haja conteúdos concretos na proposta de solução, pois, assim, é fundamental sinalizar os envolvidos na proposta de intervenção. Posto isto, Pereira (2014), a respeito da pontuação da redação do ENEM, nos ensina que:

A pontuaçáo máxima na quinta competência - 200 pontos - irá para o texto que elabora muito bem uma proposta de intervenção social que, por sua vez, está relacionada ao tema e articulada à discussão desenvolvida na redação; ou seja, a proposta de solução deve estar em consonância com o restante do texto (PEREIRA, 2014).

Convém ratificar que a prova de redaçáo do ENEM, da mesma forma que a parte objetiva deste exame, é uma avaliação de competências. Desse modo, o cerne das competências é devidamente adaptado, cujo objetivo é avaliar o desempenho do candidato como autor de um texto no qual se demonstre apto e capaz a refletir acerca do tema proposto.

Nessa direção, tal reflexão se faz a partir da leitura de textos contidos na coletânea onde se define o título, baseado no tema proposto, conjugado à leitura e da situação real da sociedade hodierna. Desse modo, o vestibulando deverá mobilizar os conhecimentos conquistados, não só ao longo do período escolar, mas também aos que adquiridos em sua experiência de vida. Assim, Carvalho (2005, p. 113) afirma que:

O modo como é elaborada a proposta, envolvendo diferentes textos que tratam de temas atuais, em diferentes linguagens e sob uma ótica também diversa, resulta em uma prova que avalia conhecimentos de diferentes áreas. Há o compromisso de que os temas abordem questóes de ordem política, social, cultural ou científica, desde que apresentados como uma situaçáo- 
problema, para a qual o autor do texto deverá propor soluçóes, respeitando os direitos humanos (CARVALHO, 2005, p. 113).

Em consonância com o exposto, a prova de redação é uma exposição de ideias, de modo a argumentar, sob um ponto de vista, o tema proposto e delinear a intervenção coerente ao o problema social apresentado, que envolve temas do cotidiano de todos, sendo exigências básicas na elaboração do texto. Além do mais, tal exame exige cada vez mais do avaliado, pois este náo objetiva somente uma simples explanação de ideias, mas a elaboraçáo de um texto de mudança, colocando possíveis soluçôes ao tema apresentado desde a sua introdução, e que também respeite aos direitos humanos.

A prova de redação do ENEM demanda que o candidato elabore sua proposta de intervenção vinculada ao tema, de modo a tecer sua discussão desenvolvida. Dessa maneira, se o texto estiver em dissonância com o que prega os direitos humanos, ou seja, se houver menção discriminatória de qualquer forma, a redação terá nota insuficiente. Leonardo (2017) destaca a importância do Direito como tema para as redaçôes, ressaltando que tal ciência é imprescindível para o vestibulando elaborar seu texto e, também, para auxiliar na construção da cidadania:

[...] os temas apresentados suscitaram aos candidatos o conhecimento básico jurídico na qual o apoio se dava desleixadamente nos textos da coletânea. [...] vislumbra-se que o Direito como tema das redaçóes vincula-se ao fato de se melhor compreender a sua dimensão no bojo da sociedade. Como exposto, evidencia-se a relevância e a premência do conteúdo jurídico com o propósito de contribuir para a Educação, além da constituição da cidadania e para a vida em sociedade (LEONARDO, 2017, p. 46-47).

Nesse sentido, os discursos de ódio são substanciados quando não se tem a demarcação da liberdade de expressão e o conceito de violação de direitos. Nesse contexto, têm-se, diariamente, situaçóes que envolvem a diversidade étnica, religiosa, regional e de gênero que são discriminadas e, mesmo com a aplicação das diretrizes, não se vê mudanças efetivas na matriz curricular e a educação para os direitos humanos permanece, em várias ocasióes, de iniciativas individuais dos educadores.

Ademais, a quinta competência, em geral, é a que apresenta a média mais baixa após as correçóes. Os temas do Enem trazem problemas de caráter social e, ao pedir uma proposta de intervenção, a instrução já deixa claro que o candidato deve optar pela conclusão do tipo soluçáo, e não do tipo resumo, por exemplo. Desse modo, ao propor uma soluçáo, o candidato deve fazê-lo com respeito aos direitos humanos (LÉLIS, 2016).

As escolas de ensino regular não preparam o educando para a compreensão do respeito aos direitos humanos, e mesmo disposto na $\mathrm{LDB} / 1996$ sendo solicitado na competência de avaliação do ENEM, esse ideal não é concretizado. É fundamental que o aluno tenha tal conhecimento básico sobre seus direitos, e cumpre ao Estado facilitar esse caminho de modo a "ensiná-los a decidir o que é melhor para eles, considerando as consequências que advirão de seus atos ou omissóes" (ROLDAN, 
2016, p. 89), pois para elaborar uma boa redação requer interdisciplinaridade para desenvolver o tema elaborado.

$\mathrm{O}$ respeito aos direitos fundamentais passou a ser obrigatório no Enem de 2013, um ano após a publicação das Diretrizes Nacionais para a Educação em Direitos Humanos. A publicação foi uma parceria entre a Secretaria de Direitos Humanos (SDH) e o Ministério da Educação (MEC) para orientar as escolas a promoverem a prática de ensino dos princípios da dignidade humana, da igualdade de direitos, do reconhecimento e da valorização das diferenças. Além disso, determina que sejam observadas a laicidade do Estado, a democracia, a sustentabilidade socioambiental, entre outros (LÉLIS, 2016).

É importante lembrar que, em 2017, o Superior Tribunal Federal decidiu e o Ministério da Educaçáo cumpriu o determinado, sendo que o candidato que não respeitar os Direitos Humanos não terá zero atribuído. Tal decisão judicial, por outro viés, permite descontar até 200 pontos dos alunos que infringirem os conceitos estabelecidos pelas Organizações das Nações Unidas na redação. Portanto, se houver dissonância com os Direitos Humanos somente haverá a perda da pontuação de uma competência, ou seja, os 200 pontos e não a perda total da pontuação (nota zero).

Diante disso, o Ministério da Educaçáo e o Instituto Nacional de Estudos e Pesquisas informaram que os participantes do ENEM, em 2017, não tiveram anulação automática na redação que violar os Direitos Humanos, como previa o Edital do Enem. Continuam em vigor os critérios de correção das cinco competências, conforme estabelecido na Cartilha de Participante - Redação no Enem 2017 (FERREIRA et al., 2017).

Além disso, Adorno (2017) explica que tal cartilha ainda apresenta exemplos de ações e ideias que violam os Direitos Humanos, tais como defesa da tortura, da mutilação ou de "qualquer forma de justiça com as próprias mãos", além de incitação as violências motivadas por "questôes de raça, etnia, gênero, credo, condição física, origem geográfica ou socioeconômica" e explicitação de qualquer tipo de discurso de ódio.

Nesse sentido, o mesmo autor completa o raciocínio ao aduzir que foi a Associação Escola Sem Partido² que pediu à Justiça para suspender essa regra, alegando que "nenhum dos candidatos deveria ser punido ou beneficiado por possuir ou expressar sua opiniáo". A entidade também disse que não existe um referencial objetivo sobre os parâmetros adotados, "impondo-se aos candidatos, em verdade, respeito ao politicamente correto" (ADORNO, 2017).

2 A Associação Escola Sem Partido é um movimento político criado em 2004 e divulgado em todo o país pelo advogado Miguel Nagib. Visa representar pais e estudantes contrários ao que chamam de "doutrinação ideológica" nas escolas (MACEDO, 2017). Ganhou notoriedade em 2015 desde que projetos de lei inspirados no movimento começaram a ser apresentados e debatidos em inúmeras câmaras municipais e assembleias legislativas pelo país, bem como no Congresso Nacional (SALES, 2017). 
Em resumo, mesmo que haja tal decisão, é necessário que o candidato apresente, em sua redação, um ideal apoiado em argumentos concretos e possíveis, além de oferecer uma proposta de intervenção solucionando (ou tentando solucionar) o problema social. A conclusão deve contemplar argumentos para cada um dos itens abordados no desenvolvimento e, mais que isso, demonstrar os seus conhecimentos e a sua coerência.

Semelhantemente, é imprescindível que a proposta obedeça aos direitos humanos, ou seja, não deve ser adversa aos valores como cidadania, liberdade, inclusão e solidariedade. Assim, vislumbra-se a necessidade de ofertar a estes alunos o prévio estudo envolvendo os Direitos Humanos, cabendo ao Estado proporcionarlhes de maneira eficaz a esse respeito.

\section{A NECESSIDADE DO EMBASAMENTO JURÍDICO EM BENEFÍCIO DOS EDUCANDOS}

De início, é mister sublinhar que há leis em nosso país que coadunam com os pensamentos de cidadania, direitos e deveres, observando-se que, por meio das noçóes de Direito formam-se alunos transformadores e críticos. Nesse viés, a escola permite o desenvolvimento do cidadão e de sua formação geral, visando a acompanhar as mudanças que vêm ocorrendo na sociedade.

A Constituição da República Federativa do Brasil de 1988, em seu artigo $3^{o}$ destaca como objetivos fundamentais da República Federativa "a construção de uma sociedade livre, justa e solidária, além da promoção do bem de todos; a erradicação da pobreza e redução das desigualdades, entre outros" (BRASIL, 1988). Para que estes objetivos sejam positivados, portanto, deve-se ter atenção do Estado e dos educadores, de modo a incitar seus alunos ao civismo e a cultura jurídica, viabilizando o efetivo acesso à justiça.

Nesse caminho, a escola deve preparar o aluno para o convívio social, todavia o que se tem visto é uma política excludente, pois nota-se que a falta de conhecimento da sociedade a mantém numa hierarquia de passividade em relaçáo às questôes políticas e socioeconômicas no país, uma vez que, aquele que é o detentor de informaçóes, tem o poder, exigindo seus direitos. Bonavides et al. (2012, p. 55) destacam o conceito de cidadania:

[...] cidadania é a condição de acesso aos direitos sociais (educação, saúde, segurança, previdência) e econômicos (salário justo, emprego) que permite que o cidadão possa desenvolver todas as suas potencialidades, incluindo a de participar de forma ativa, organizada e consciente, da construção da vida coletiva no Estado democrático (BONAVIDES, et al., 2012, p. 55).

Com fulcro no que dispóe a Lei Maior em relação aos direitos sociais, com a oferta do ensino jurídico nas escolas regulares, seja na inclusão destes na matriz curricular ou por meio de palestras, os alunos estariam aptos a participarem ativamente dos assuntos sociais, pois os deveres e direitos do ser humano devem estar juntos buscando uma sociedade humanizada, justa, democrática e igualitária 
e, é por meio da educaçáo, fundada na mudança da realidade de maneira efetiva, concreta e objetiva que tais fundamentos poderão ser contemplados.

Arendt (1987) concebe a cidadania como o "direito a ter direitos, considerado como primeiro direito fundamental, do qual os demais se derivam". Em outras palavras, a cidadania encaixa-se como direito fundamental do cidadão, embora disposto como direito fundamental. Assim sendo, a cidadania precisa ser conquistada, uma vez que resulta de um agir conjuntamente com toda sociedade, sendo uma construção coletiva, insurgindo-se, todavia, à oferta de privilégios, não sendo revogada ou apartada.

Ademais, o que se busca é que o jovem tenha consciência de seus direitos e deveres e, sobretudo, entenda onde procurá-los e saiba como colocá-los em prática, pois a desinformação restringe a prática da cidadania, de modo a impedir a prática social plena dos desfavorecidos. As noçóes jurídicas contribuem com a cidadania, além de deixar os alunos informados dos assuntos corriqueiros, auxiliando no desenvolvimento textual das redaçóes.

Weber et al. (1971) preconiza que "a escola náo pode ser hermética, pois se trata de uma relaçáo interpessoal, por meio de um conjunto de normas comportamentais que orientam as interaçôes entre membros de uma sociedade". O sociólogo alemão Marshall (1967) enfatiza que direitos sociais estão pautados na Igualdade (Direito Civil), Participação (Direito Político) e Social (Direito Social), e sustenta que a cidadania só é plena se dotada dessa trilogia do direito.

Não obstante, é bom salientar que o Direito não deve ficar adstrito ao âmbito universitário, já que é de interesse público, e retê-lo dessa forma, proporciona a progressão da desigualdade social, pois esta ciência se divide em dois grandes pilares, o Público e o Privado, sendo de suma importância seu entendimento por toda coletividade, já que sáo organizados com normas que atribuem à administração pública e aos particulares direitos e deveres a fim de geri-los da melhor forma possível em benefício da coletividade.

Assinale, ainda, que o artigo $3^{\circ}$ da Lei de Diretrizes e Bases, de 1996, dispóe que "O ensino será ministrado com base nos seguintes princípios: I - igualdade de condiçôes para o acesso e permanência na escola" (BRASIL, 1996). De igual sorte, a referida lei educacional faz referência a função social da educação, cujo processo de formação de sujeitos é uma ação guiada por familiares e pela sociedade, tendo como destaque o Estado, os responsáveis, educadores e a escola, que têm por escopo dar condiçóes ao educando de se ter uma visão abrangente, participativa e crítica do mundo que o cerca, pois desta maneira é possível se falar em interação harmoniosa com a sociedade hodierna.

O Direito deveria estar inserto nas escolas regulares desde a Educação Infantil, pois quando o aluno alcançar ao Ensino Médio terá um maior conhecimento de tais temas que são de suma importância para ele, são condições "sine qua non" nas quais este cidadáo estaria sendo preparado para atuar e exercer sua cidadania após o egresso da escola regular. Desse modo, a educação deve ser ofertada e democrática, 
sempre, a todos, valendo-se do princípio da isonomia que reza que todos são iguais perante a lei, sem distinção de qualquer natureza (BRASIL, 1988).

Nesse diapasão, o ensino básico-jurídico está concatenado ao que legisla a Carta Magna, bem como a Lei de Diretrizes e Bases da Educação, de 1996 e será peremptório à formação dos alunos que poderão conhecer os fundamentos de tais dispositivos. Assim, compenetrados ao princípio da dignidade humana e sabedores dos direitos fundamentais, estarão mais aptos ao exercício da cidadania, e desempenharão sua função social e no mercado de trabalho.

Por outro prisma, devido os entraves e dificuldades que garantem o acesso à justiça, surge o fato que levanta a questão de que a falta de informação acerca dos direitos gera um afastamento entre o indivíduo, titular de direitos e os seus direitos. Cappelletti e Garth (1988, p. 23) aduzem que:

Num primeiro nível está a questão de reconhecer a existência de um direito juridicamente exigível. Essa barreira fundamental é especialmente séria para os despossuídos, mas não afeta apenas os pobres. Ela diz respeito a toda a população em muitos tipos de conflitos que envolvem direitos. [...] Mesmo consumidores bem informados, por exemplo, só raramente se dão conta de que sua assinatura num contrato náo significa que precisem, obrigatoriamente, sujeitar-se a seus termos, em quaisquer circunstâncias. Falta-lhes o conhecimento jurídico básico não apenas para fazer objeção a esses contratos, mas até mesmo para perceber que sejam passíveis de objeçáo (CAPPELLETTI; GARTH, 1988, p. 23).

Em consonância com o exposto, conforme dispóe a Constituição Federal, de 1988, em seu artigo 205, destaca que a educação, direito de todos e dever do Estado e da família, será promovida e incentivada com a colaboraçáo da sociedade, visando ao pleno desenvolvimento da pessoa, seu preparo para o exercício da cidadania e sua qualificação para o trabalho (BRASIL, 1988).

Por esses fatos, ressalta-se a tese de que um currículo inovador direcionado aos direitos sociais estabelece uma ferramenta primacial ao indivíduo, dandolhe conhecimento, "pois só a educação liberta para a vida e constrói a verdadeira cidadania" (MATO GROSSO DO SUL, 2012, p. 05) e, assim, a escola desempenharia um papel pedagógico e educativo, de sobremodo a auxiliar com a redução no déficit de cidadania que acompanha os grupos sociais marginalizados.

Pode-se afirmar que, o estudo de conhecimentos básicos de direito, com objetivo de atingir efetivamente as metas traçadas à educação, proporcionaria um progresso no acesso à justiça, tornando o aluno consciente, além de contribuir ao exercício da cidadania, e, também, auxilia no desenvolvimento textual daqueles que realizarão provas de Redação, uma vez que "torna-se modalizado pelo querer e pelo dever, escreve de modo a agradar e mostrar-se solidário aos valores disseminados pelos temas e figuras no enunciado da proposta na qual o direito tem papel fundamental" (LEONARDO, 2017, p. 95).

Com efeito, sendo a justiça a virtude pela qual cada um possui o próprio (autonomia), a dicotomia manifestada na linguagem popular - legal/igual - marca 
dois modos de se estabelecer o que é devido a outrem: pela lei ou pela igualdade (ARISTÓTELES, 1990, p. 1366). Contudo, conforme Bobbio (1992), em relação ao direito ao Ensino Médio, enquanto a universalização não der a possibilidade desse direito ser efetivado, por este não ser obrigatório, tal direito será dependente do interesse de cada um.

A inserção jurídica, de forma básica e ligada a temas transversais, tem base constitucional e na LDB. Tal inclusão deveria ser universal, uma vez que, na medida em que se estabelece a progressiva universalização, o Estado deveria dar mais condiçôes par esse ideal, a fim de que as noçôes do direito fossem realmente democratizadas. Sobre a inserção do direito, Leonardo (2017, p. 347) destaca tal possibilidade, pois:

[...] a inserção jurídica está amplamente amparada pela Carta Magna e pela lei sobre a Educação, a Lei de Diretrizes e Bases LDB, de 1996, vislumbrando total legalidade desde a sua elaboração até sua sanção e por meio da educação pode-se identificar os meios mais aptos à efetivação da justiça constitucional (LEONARDO, 2017, p. 347).

Em última análise, considera-se a justificativa de se propor atividades destinadas ao Ensino Jurídico básico nas escolas regulares, como sendo uma das formas que poderão contribuir significativamente, não só para a formaçáo integral do educando, mas, também, para melhor prepará-lo para uma abordagem adequada da questáo no vestibular, seja para o benefício dos educandos em relação ao conhecimento de direitos e deveres visando ao exercício da cidadania, seja, também, para auxiliá-los nas redações, uma vez que tal ideal exige certa maturidade intelectual para sua compreensáo, ou seja, as atividades devem variar de acordo com a idade do sujeito porque contribuiria para a melhor captação do conteúdo exposto e ao desenvolvimento crítico.

\section{CONSIDERAÇÓES FINAIS}

O percurso teórico-metodológico da competência do ENEM que reza que o texto deve estar em consonância com o que pregam os Direitos Humanos tem como objetivo instaurar à produção escrita à circunstância de gênero textual, instituído, simultaneamente, de uma mostra e de uma transgressão, compreendida como aspecto constitutivo do texto, conquanto consequência de uma experiência de linguagem onde se mostra necessariamente importante que os alunos tenham contato com a temática nas escolas regulares. Pretendeu-se desenvolver o tema a fim de melhor compreender a sua dimensão no bojo dos problemas sociais abordados nos temas das redaçóes.

Dessa maneira, buscou-se analisar, primeiramente, os Direitos Humanos e Educação inerentes à concepção de dignidade humana, onde se teve como ponto de partida a análise da natureza do ensino nacional e a necessidade de suas transformaçôes imprescindíveis aos que se solicita para elaboração textual cujo objetivo dos educandos é alcançar o Ensino Superior. 
Ressaltou-se que a ausência da concessão de uma base sólida ao ensino dos Direitos Humanos não apresenta respostas afirmativas capazes de suprir essa lacuna tornando o educando hábil a realizar o que fora solicitado como competência de avaliação nas redaçôes do ENEM.

Por esse prisma, mostrou-se a importância de considerar os Direitos Humanos como uma mudança importante no que se refere à Educação, aliado à educaçáo popular e seus movimentos, cujo processo busca a uma educação livre e solidária, pois se de um lado contribui para se realizar com condiçóes totais os textos, por outro lado, contribui com o exercício da cidadania. A propósito, salientou-se que a Constituiçáo Federal de 1988 contempla como um de seus fundamentos a cidadania e, dessa forma, coopera e fortalece o elo social entre a sociedade e a educaçáo.

Destacou-se a relevância da Declaração Universal dos Direitos do Homem, 1948, que foi responsável por desatar a particularidade da educação, uma vez que "deve visar à plena expansão da personalidade humana e ao reforço dos direitos do Homem e das liberdades fundamentais" (DECLARAÇÃO UNIVERSAL DOS DIREITOS HUMANOS, 1948), e balizou uma nova ideia acerca dos direitos humanos, como universais e indivisíveis devendo o ensino ser acessível para todas as classes sociais.

Assim, a partir de 1988, com a Constituição Brasileira, veio à tona o marco da democracia no Brasil e a oficialização dos direitos humanos. Dessa maneira, destacou-se o valor da dignidade humana como princípio fundamental, valor intrínseco a cada cidadão. De igual modo, originou-se uma dimensão comunitária que revela a responsabilidade de cada um em relação à dignidade e respeito ao outro que compóe a sociedade.

Destarte, a Lei Maior de 1988 deu força principiológica à Educação, tornando-a vetor interpretativo da isonomia desse direito social ao dedica-lo como um direito fundamental e deixou o Estado como responsável pela missão de fomentar medidas que satisfaçam seus ideais. Nessa direção, antes de ser meramente norma programática, instaurou-se com o caráter de força vinculativa para o Estado.

Entretanto, a importância do presente estudo residiu, pois, na constatação de que se faz necessária a oferta do ensino igualitário, de modo a incluir noçóes do Direito e dos Direitos Humanos no ambiente escolar público, pois se o próprio Exame Nacional do Ensino Médio, que visa o ingresso dos alunos ao Ensino Superior, solicita o entendimento desses direitos, compete-lhe de modo a suprir tal lacuna ainda existente na educação do país.

Constatou-se, também, que tal ausência em relaçáo a este direito social atinge os educandos; implica em desrespeito ao direito fundamental no ambiente escolar saudável, provocando repercussóes em toda a sociedade, uma vez que o ensino sobre os Direitos Humanos voltados para redação do ENEM náo é lecionado em escolas regulares.

Portanto, conclui-se que é imprescindível satisfazer a demanda em relaçáo a esta competência, à medida que, sua ausência viola os direitos dos educandos. 
Por outro viés, é necessário considerar que perante a escassez acerca do tema, cabe ao Estado buscar soluçóes para resolução desse conflito decorrente da ausência no contexto das relaçóes educacionais.

Quanto à resposta do Estado aos alunos e sociedade, devido uma questáo legislativa, a incumbência é da União em prover a Educação e alterar o currículo de modo a se incluir noçóes jurídicas, e que ainda há um descompasso entre as referências teóricas e o que se avalia nas competências das redaçóes do ENEM. É certo que houve avanço em prol dos direitos fundamentais e da Educação com a promulgação da Constituição Federal de 1988 e da Lei de Diretrizes e Bases da Educação Nacional; náo menos certo, porém, é o fato de haver uma cultura da própria legislação resistente ao ensino básico jurídico nas escolas regulares.

\section{REFERÊNCIAS}

ADORNO, Luís. ENEM - Ferir direitos humanos náo zera redaçáo do Enem, mas tira pontos; entenda. 2017. Disponível em: https://educacao.uol.com.br/ noticias/2017/11/04/desrespeitar-direitos-humanos-nao-zera-redacao-do-enem-mas-tiraate-200-pontos.htm. Acesso em: $06 \mathrm{dez} 19$.

ARENDT, Hannah. A condiçáo humana. Rio de Janeiro: Forense universitária, 1987.

ARISTÓTELES. Retórica. Tradução Antonio Tovar. Madri: Centro de Estudios Constitucionales, 1990.

BOBBIO, Norberto. A Era dos Direitos. Rio de Janeiro: Campus, 1992.

BONAVIDES, Paulo; MIRANDA, Jorge; AGRA, Walber de Moura. Comentários à Constituiçáo Federal de 1988. São Paulo: Ed. Atlas - 2012.

BRASIL. Constituiçáo da República Federativa do Brasil. Brasília, DF: Senado Federal: Centro Gráfico, 1988. 292 p.

BRASIL. Lei no 9496/96 de 20 de dezembro de 1996. Dispóe sobre o sistema de educação brasileiro com base nos princípios presentes na Constituição.

Disponível em: $<$ http://pt.wikipedia.org/wiki/Lei_de_Diretrizes_e_Bases_da_ Educa\%C3\%A7\%C3\%A3o_Nacional>. Acesso em: $20 \mathrm{dez}$ de 2019.

CLAUDE, Richard Pierre. Direito à educação e educação para os direitos humanos.

Revista Internacional de Direitos Humanos, a, v. 2, 2005.

DECLARAÇÃO UNIVERSAL DOS DIREITOS HUMANOS. Assembleia Geral das Naçóes Unidas em Paris. 10 dez. 1948. Disponível em: http://www.ohchr.org/EN/ UDHR/Documents/UDHR_Translations/por.pdf. Acesso em: 26 jun. 2017.

CAPPELLETTI, Mauro; GARTH, Bryant (colab.). Acesso à Justiça. Tradução de Ellen Gracie Northfleet. Porto Alegre, Fabris, 1988. 
CARVALHO, Reginaldo Pinto de. Metodologia de correçáo da Redaçáo do Enem. Instituto Nacional de Estudos e Pesquisas Educacionais Anísio Teixeira. INEP. Brasília. 2005.

FERREIRA, Afonso; AZEVEDO, Guilherme; ADORNO, Luís. 2017. MEC acata decisáo e diz que desrespeitar direitos humanos não zera redaçáo do ENEM.

Disponível em: https://educacao.uol.com.br/noticias/2017/11/04/redacao-do-enem-quedesrespeitar-direitos-humanos-nao-sera-zerada-definem-inep-e-mec.htm. Acesso em: 06 $\operatorname{dez} 17$.

FREIRE, Paulo. Educaçáo como prática da liberdade. 14 ed. Rio de Janeiro: Paz e Terra, 2011.

GADOTTI, Moacir. A questão da educação formal/não-formal. Sion: Institut Internacional des Droits de 1० Enfant, p. 1-11, 2005.

LÉLIS, Ena. A quinta competência do ENEM. Falamos sobre isso no Jornal Correio. 2016. Disponível em: http://redacaonotadez.com.br/blog/quinta-competencia-enem/. Acesso em: 07 ago 2019.

LEONARDO, Francisco Antonio Morilhe. A importância do direito como tema das redaçôes e a efetividade do direito à educação. Revista Horizontes, v. 35, n. 2, p. 89-97, mai./ago. 2017.

LIU, Emiliano Palmada; PINI, Francisca Rodrigues de Oliveira; GÓES, Washington. Educaçáo Popular. São Paulo: Instituto Paulo Freire, 2011. (Caderno MOVA-Brasil, v.3).

MACEDO, Elizabeth. As demandas conservadoras do movimento escola sem partido e a base nacional curricular comum. Educaçáo \& Sociedade, v. 38, n. 139, p. 507-524, 2017.

MALIK, Charles. These Rights and Freedoms. Naçóes Unidas: Department of Public Information, 1950.

MARSHALL, Thomas Humphrey. Cidadania, classe social e status. Rio de janeiro: Zahar, 1967.

MATO GROSSO DO SUL. Secretaria de Estado de Educação - SED. Superintendência de Políticas de Educação. Referencial Curricular da Educaçáo Básica da Rede Estadual de Ensino - cadernos Ensino Fundamental e Ensino Médio, 2 vols. Campo Grande, MS, 2012.

PEREIRA, Camila Dalla Pozza. Esclarecimentos sobre a $5^{\mathbf{a}}$ competência da redaçáo do Enem. 2014. Disponível em: https://www.infoenem.com.br/esclarecimentos-sobre-a-5acompetencia-da-redacao-do-enem/. Acesso em: 07 ago 2019. 
REGO, Sérgio. A educação médica e o Plano Nacional de Educação em Direitos Humanos no Brasil. Rev. bras. educ. med., Rio de Janeiro, v. 34, n. 4, p. 479-480, Dec. 2010.

ROLDAN, Rosilma. Como ensinar Direito para Crianças e Jovens: Desafios, dúvidas, estratégias, reflexóes e experiências. São Paulo. $1^{\circ}$ Ed. 146 p. 2016.

SÃO PAULO. Secretaria da Educação. Proposta curricular do Estado de São Paulo: Sociologia. São Paulo: SEE, 2009.

SALLES, Diogo da Costa. As bases do conceito de "doutrinação ideológica" do Movimento Escola Sem Partido na obra de Nelson Lehmann da Silva. Anais do XXIX Simpósio Nacional de História, Brasília/DF, 2017.

WEBER, Max; GERTH, Hans Heinrch; MILLS, C. Wright. Ensaios Sociologia 2. Ed. Rio de Janeiro: Zahar, 1971. 